\title{
Investigation of the cytotoxicity, apoptosis and pharmacokinetics of Raddeanin A
}

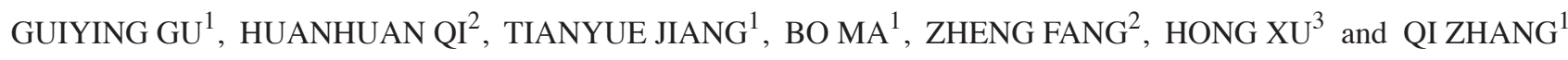 \\ Schools of ${ }^{1}$ Pharmaceutical Sciences, ${ }^{2}$ Biotechnology and Pharmaceutical Engineering, ${ }^{3}$ College of Food Science \\ and Light Industry, Nanjing Tech University, Nanjing, Jiangsu 210009, P.R. China
}

Received June 29, 2015; Accepted October 24, 2016

DOI: $10.3892 / \mathrm{ol} .2017 .5588$

\begin{abstract}
Raddeanin A, one of the triterpenoid saponins extracted from Anemone raddeana rhizome of the Ranunculaceae family, has demonstrated the ability to inhibit the growth of human hepatic and gastric cancer cells. However, the effects of Raddeanin A on human colon cancer cells have not been investigated extensively. The present study aimed to examine the antiproliferative and apoptosis-inducing effects of Raddeanin A on the HCT-116 human colon cancer cell line in vitro, and evaluate the pharmacokinetic and biodistribution properties of Raddeanin A in mice following a single oral administration. A 3-(4,5-dimethylthiazol-2-yl)-2,5-diphenyltetrazolium bromide assay was used to assess the in vitro cytotoxicity of Raddeanin A against HCT-116 cells. 4',6-Diamidino-2-phenylindole, dihydrochloride staining and flow cytometry were performed to further examine the apoptosis-inducing capability of Raddeanin A. The concentrations of Raddeanin A in the plasma and tissues were analyzed using liquid chromatography-tandem mass spectrometry. Raddeanin A showed a dose-dependent antiproliferative effect towards the HCT-116 cells, with a half maximal inhibitory concentration of $\sim 1.4 \mu \mathrm{M}$. Treatment with Raddeanin A resulted in a significant induction of apoptosis, observed as apparent morphological changes of the nuclei, with a total apoptotic ratio of $41.8 \%$ at a concentration of $3 \mu \mathrm{M}$. Low concentrations of Raddeanin A were detected in the heart, liver, spleen, lung, kidney and plasma of the mice following oral administration, however, the majority of the Raddeanin A was distributed in the intestinal tract, particularly in the colon and caecum. These present study confirmed the growth-inhibitory and apoptosis-inducing effects of Raddeanin A on HCT-116 cells and performed preliminary examinations of its pharmacokinetic properties,
\end{abstract}

Correspondence to: Dr Qi Zhang, School of Pharmaceutical Sciences, Nanjing Tech University, 5 Xinmofan Road, Nanjing, Jiangsu 210009, P.R. China

E-mail: nancyzhang03@hotmail.com

Key words: Raddeanin A, cytotoxicity, cellular uptake, apoptosis, pharmacokinetics which provide a foundation for further investigating the inhibitory mechanism on the colon cancer cells in vivo.

\section{Introduction}

Anemone raddeana of the family Ranunculaceae is a traditional medicine, which was widely used by the Chinese in ancient times to promote the excretion of urine and expel excess gas. At present, with the development of separation and purification techniques, several constituents of Anemone raddeana have been isolated and identified (1), which is convenient for examining the mechanism of single components.

Raddeanin A, a primary triterpenoid saponin extracted from Ranunculaceae Anemone raddeana rhizome (2), has shown antiproliferative effects on human hepatic cancer cells (3). Previous studies have also shown that Raddeanin A induces apoptosis and inhibits invasion in human gastric cancer cells (4), and Raddeanin A has a significant inhibitory effect on the growth of tumor cells, including S180, H22 and U14 cells, in vivo (5). All these activities suggest that Raddeanin A may be a potential compound for the treatment of cancer, and a focus is required on its further investigation and therapeutic application.

However, the inhibitory effect of Raddeanin A on HCT-116 colon cancer cells has not been reported, and few investigations have been performed on the pharmacokinetics and tissue distribution in mice following oral administration of Raddeanin A, which are important in the development of novel drugs (6).

The present study aimed to investigate the inhibitory activity of Raddeanin A on the growth of HCT-116 colon cancer cells. In addition, detailed investigations of the in vivo pharmacokinetic and tissue distribution of Raddeanin A were performed.

\section{Materials and methods}

Chemicals and instruments. Raddeanin A (purity >98\%) was purchased from the National Institute for the Control of Pharmaceutical and Biological Products (Beijing, China). Digoxin, used as internal standard (IS; purity $>98.0 \%$ ) was obtained from Sichuan Weikeqi Biological Technology Company (Chengdu, China). Formic acid of a liquid chromatography-mass spectrometry (LC-MS) grade was purchased 
from Sigma-Aldrich (Merck Millipore, Darmstadt, Germany). High performance liquid chromatography (HPLC) gradient grade methanol and acetonitrile were purchased from Merck Millipore. Milli-Q water was produced using a Millipore purification system (EMD Millipore, Billerica, MA, USA). Trypsin-ethylene diamine tetraacetic acid (EDTA) solution $(0.25 \%)$ was obtained from Biosharp (Hefei, China) and 3-(4,5-dimethylthiazol-2-yl)-2,5-diphenyltetra-zolium bromide (MTT) was purchased from Sigma-Aldrich. An AnnexinV-fluorescein isothiocyanate (FITC)/propidium iodide (PI) detection kit was supplied by BD Biosciences (Franklin Lakes, NJ, USA).

An LC-MS/MS system was used in the present study, the HPLC system consisted of two LC-20AD pumps, a DGU-20A3 degasser, an SIL-20AC auto sampler and a CTO-20AC column oven (Shimadzu Corporation, Kyoto, Japan). The MS was achieved on an API 4000 Q-trap MS/MS system (Applied Biosystems; Thermo Fisher Scientific, Inc., Waltham, MA, USA) equipped with a Turbo Ion Spray inlet in the negative ion mode. Quantification was performed using multiple reaction monitoring mode.

\section{Cell experiments}

Cell line and cell culture. The HCT-116 human colorectal carcinoma cells, obtained from American Type Culture Collection (Manassas, VA, USA), were cultured at $37^{\circ} \mathrm{C}$ in Dulbecco's modified Eagle's medium (Gibco; Thermo Fisher Scientific, Inc.), supplemented with $10 \%$ heat-treated fetal bovine serum (FBS; HyClone; GE Healthcare Life Sciences, Logan, UT, USA), $100 \mathrm{U} / \mathrm{ml}$ penicillin and $100 \mu \mathrm{g} / \mathrm{ml}$ streptomycin. The cells were incubated in an atmosphere of $95 \%$ air and $5 \% \mathrm{CO}_{2}$. The cells were stained by the addition of $0.04 \%$ trypan blue to the culture medium to determine cell viability.

MTT assay. The cells were seeded in a 96-well plate at a density of $1 \times 10^{4}$ cells $/ 0.2 \mathrm{ml} /$ well. Following stabilization overnight, the cells were suspended in serum-free medium with a range of concentrations of Raddeanin A $(0.1,0.5,1,5,10,50,100$ and $200 \mu \mathrm{M})$. Following treatment for 12, 24 and $48 \mathrm{~h}$, MTT (20 $\mu \mathrm{l} ; 5 \mathrm{mg} / \mathrm{ml}$; Sigma-Aldrich; Merck Millipore) was added into each well and the plates were placed in a $37^{\circ} \mathrm{C}$ incubator for $3 \mathrm{~h}$. Following incubation, the medium was discarded and $150 \mu 1$ DMSO (Sigma-Aldrich; Merck Millipore) was added. The absorbance at a wavelength of $490 \mathrm{~nm}$ was measured using a microplate reader (BioTek Instruments, Inc., Winooski, VT, USA).

Cellular uptake. The HCT-116 cells were seeded at a density of $2 \times 10^{4} / \mathrm{ml}$ in a 6 -well plate and incubated with Raddeanin A $(0.25,0.5,1$ and $2 \mu \mathrm{M})$ for 12,24 and $48 \mathrm{~h}$ at $37^{\circ} \mathrm{C}$. On harvesting, the cell culture media were collected for analysis. The cells were harvested using $0.25 \%$ Trypsin-EDTA Solution following being washed twice with cooled PBS. The solution was then centrifuged at $1,000 \mathrm{x} \mathrm{g}$ for $10 \mathrm{~min}$ at $4^{\circ} \mathrm{C}$ to obtain the precipitates. All samples were stored at $-70^{\circ} \mathrm{C}$ until analysis.

DAPI staining. DAPI, a blue fluorescent dye, preferentially stains double-stranded DNA and produces an enhanced florescence. In the present study, the cells were seeded at a density of $2 \times 10^{4} / \mathrm{ml}$ and incubated with Raddeanin A (1 and $\left.3 \mu \mathrm{M}\right)$ for
$24 \mathrm{~h}$ at $37^{\circ} \mathrm{C}$. Subsequently, $4 \%$ paraformaldehyde was added to fix the cells and, $30 \mathrm{~min}$ later, DAPI $(5 \mu \mathrm{g} / \mathrm{ml})$ was added and the plate was incubated at room temperature for $15 \mathrm{~min}$. The cells were then observed under a fluorescent microscope in bright field with a DAPI filter at 200x magnification.

Flow cytometric analysis of levels of apoptosis using AnnexinV-FITC/PI double staining. Following treatment of the cells with or without Raddeanin A (1 and $3 \mu \mathrm{M}), \sim 3 \times 10^{5}$ cells were harvested. Subsequent to being washed twice with cold PBS, the cells were re-suspended in $500 \mu \mathrm{l}$ binding buffer, containing $10 \mathrm{mM}$ Hepes/NaOH (pH 7.4), $140 \mathrm{mM} \mathrm{NaCl}$ and $2.5 \mathrm{mM} \mathrm{CaCl}_{2}$. Annexin-V (5 $\left.\mu \mathrm{l}\right)$ and PI $(5 \mu \mathrm{l})$ were then added, and incubated at room temperature for $15 \mathrm{~min}$ in the dark for flow cytometric analysis.

\section{Pharmacokinetic investigations in mice}

Sample preparation. The analytical method used was developed and validated in a previous study (7) and was successfully applied in the present study. Samples of plasma from mice used for pharmacokinetic investigation (100 $\mu \mathrm{l})$ were spiked with $10 \mu \mathrm{I}$ IS solution $(10 \mu \mathrm{g} / \mathrm{ml})$ and then vortexed for $3 \mathrm{~min}$. Subsequently, $400 \mu \mathrm{l}$ methanol was added and immediately vortexed for $5 \mathrm{~min}$, followed by centrifugation for $10 \mathrm{~min}$ at $12,000 \mathrm{x} \mathrm{g}$ at $4^{\circ} \mathrm{C}$. A $350 \mu \mathrm{l}$ volume of the supernatant was then transferred into a separate $1.5 \mathrm{ml}$ centrifuge tube and evaporated to dryness in a vacuum desiccator. The residue was reconstituted in $100 \mu \mathrm{l}$ methanol-water $(50: 50, \mathrm{v} / \mathrm{v})$, vortexed for $5 \mathrm{~min}$ and then centrifuged at $12,000 \mathrm{x}$ g for $10 \mathrm{~min}$ at $4^{\circ} \mathrm{C}$. A $5 \mu \mathrm{l}$ aliquot of the solution was injected into the LC-MS/MS system. Data acquisition was performed using Analyst 1.5.1 software (Applied Biosystems; Thermo Fisher Scientific, Inc.).

Pharmacokinetics investigation. A total of $60 \mathrm{BALB} / \mathrm{c}$ mice (24-30 g; 30 females and 30 males) aged 6 weeks were used for the pharmacokinetic analyses. Mice were supplied bu the Experimental Animal Center of Yangzhou University (Jiangsu, China). All animals had free access to food and water. All animals were housed in an environmentally controlled breeding room at a temperature of $\sim 25^{\circ} \mathrm{C}$ under a $12 \mathrm{~h}$ light $/ 12 \mathrm{~h}$ dark cycle for at least 1 week prior to the start of the experiments. The mice were fasted for $12 \mathrm{~h}$ with free access to water prior to each experiment. The present study was approved by the Animal Ethical Committee of Nanjing Tech University (Nanjing, China). The 60 mice were orally administered once with Raddeanin A $(1.5 \mathrm{mg} / \mathrm{kg})$. Blood samples were collected into heparinized tubes at $0 \mathrm{~h}$ (pro-drug) and at 0.08, 0.17, 0.33, $0.5,1,1.5,2,3,4,6$ and $8 \mathrm{~h}(\mathrm{n}=5)$. The plasma samples were acquired by centrifugation at $3,500 \mathrm{x}$ g for $10 \mathrm{~min}$ at $4^{\circ} \mathrm{C}$ and then stored at $-80^{\circ} \mathrm{C}$ until analysis.

Tissue distribution in mice. For investigating the tissue distribution of Raddeanin A, an additional $20 \mathrm{BALB} / \mathrm{c}$ mice (10 females and 10 males; 24-30 g; aged 6 weeks; free access to food and water; Experimental Animal Center of Yangzhou University) were assigned into four groups. Samples of the heart, liver, spleen, lung, kidney, stomach, dodecadactylon, jejunum, ileum, colon, caecum and rectum $(\sim 0.2 \mathrm{~g})$ were collected at $0,0.4,1$ and $4 \mathrm{~h}$ (following sacrifice by cervial dislocation) following an oral administration of Raddeanin 
A solution $(1.5 \mathrm{mg} / \mathrm{kg})$. The tissue samples were rinsed with ice-cold saline solution $(0.9 \% \mathrm{NaCl})$ to remove the blood. All samples were stored at $-20^{\circ} \mathrm{C}$ until LC-MS/MS analysis.

Data analysis. Pharmacokinetic parameters were calculated using DAS version 2.0 software (Mathematical Pharmacology Professional Committee of China, Shanghai, China). Data are expressed as the mean \pm standard deviation. The significance of differences in the data was evaluated using student's $t$ test. $\mathrm{P}<0.05$ was considered to indicate a statistically significant difference. Statistical analysis was performed using SPSS version 16.0 (SPSS, Inc., Chicago, IL, USA).

\section{Results}

\section{Cell experiments}

MTT assay. Following treatment of the HCT-116 cells with Raddeanin A for 12, 24 and $48 \mathrm{~h}$, the viability of the cells was assessed using an MTT assay. The results, as shown in Fig. 1, indicated that the inhibitory effect of Raddeanin $\mathrm{A}$ on the HCT-116 was dose-dependent and time-independent. When treated with the dose of $5 \mu \mathrm{M}$ Raddeanin A for 12, 24 and $48 \mathrm{~h}$, the percentages of viable cells declined to $24.19,17.31$ and $8.18 \%$, respectively. The half maximal inhibitory concentration $\left(\mathrm{IC}_{50}\right)$ values of Raddeanin A on the HCT-16 cells treated for 12, 24 and $48 \mathrm{~h}$ were $1.376,1.441$ and $1.424 \mu \mathrm{M}$, respectively. According to the results of the MTT assay, 1 and $3 \mu \mathrm{M}$ of Raddeanin A were selected to for the subsequent DAPI staining and flow cytometric analysis experiments.

Cellular uptake. The cellular uptake of Raddeanin A was evaluated by co-incubating HCT-116 cells with a range of drug concentrations for 12, 24 and $48 \mathrm{~h}$. As shown in Fig. 2, the results demonstrated that the uptake of Raddeanin $\mathrm{A}$ in the HCT-116 cells was dose-dependent, however no time-dependency was observed.

DAPI staining. As shown in Fig. 3, compared with the nuclei of the untreated cells, which exhibited a round or oval shape and were used as a control, Raddeanin A exerted a marked effect on the induction of cell apoptosis, visible from the occurrence of distinct nuclear morphological changes of apoptosis, including chromatin condensation, shrinkage and apoptotic body formation.

Flow cytometric analysis of apoptosis using AnnexinV-FITC/ $P I$ double staining. To further examine the apoptosis-inducing capability of Raddeanin A quantitatively, flow cytometric analysis was performed. The results (Fig. 4) showed that the percentages of viable, early apoptotic, late apoptotic and necrotic cells altered significantly following treatment with different concentrations of Raddeanin A for $24 \mathrm{~h}$. The total apoptotic ratio reached $41.8 \%$ at the concentration of $3 \mu \mathrm{M}$, as evidenced by a clear shift from the live cell population to early and late apoptotic cell populations.

\section{Pharmacokinetic investigations in mice}

Pharmacokinetic investigations. The mean plasma concentration-time graph of Raddeanin A is shown in Fig. 5. The major pharmacokinetic parameters of Raddeanin A calculated using
Table I. Pharmacokinetic parameters of Raddeanin A in mouse plasma following oral administration.

\begin{tabular}{lc}
\hline Parameter & Value \\
\hline $\mathrm{AUC}_{(0-\mathrm{t})}\left(\mu \mathrm{g} / \mathrm{l}^{*} \mathrm{~h}\right)$ & $24.247 \pm 0.458$ \\
$\mathrm{AUC}_{(0-\infty)}\left(\mu \mathrm{g} / \mathrm{l}^{*} \mathrm{~h}\right)$ & $28.760 \pm 0.592$ \\
$\mathrm{MRT}_{(0-\mathrm{t})}(\mathrm{h})$ & $2.413 \pm 0.022$ \\
$\mathrm{t}_{1 / 2}(\mathrm{~h})$ & $3.542 \pm 0.158$ \\
$\mathrm{~T}_{\max }(\mathrm{h})$ & $0.330 \pm 0.000$ \\
$\mathrm{CL}(\mathrm{l} / \mathrm{h} / \mathrm{kg})$ & $69.564 \pm 1.435$ \\
$\mathrm{~V}(\mathrm{l} / \mathrm{kg})$ & $355.429 \pm 14.054$ \\
$\mathrm{C}_{\max }(\mu \mathrm{g} / \mathrm{l})$ & $12.326 \pm 0.598$ \\
\hline
\end{tabular}

Values are presented as the mean \pm standard deviation. AUC, area under curve; MRT, mean residence time; $\mathrm{t}_{1 / 2}$, half-life; $\mathrm{T}_{\max }$, time to maximum concentration; $\mathrm{CL}$, clearance; $\mathrm{V}$, volume; $\mathrm{C}_{\max }$, maximum concentration.

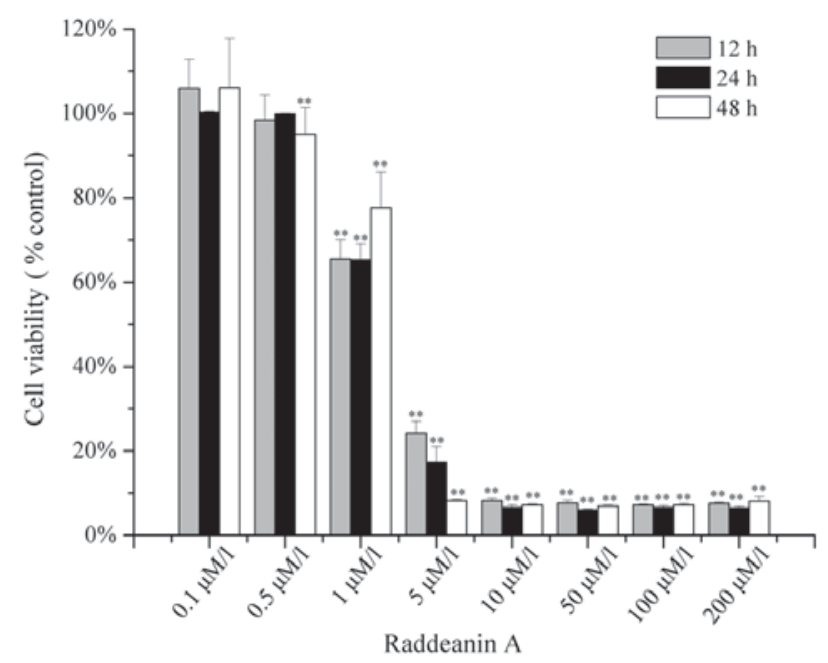

Figure 1. Cell viability of the HCT-116 cells following treatment with Raddeanin A $(0.1,0.5,1,5,10,50,100$ and $200 \mu \mathrm{M} / 1)$ for 12,24 and $48 \mathrm{~h}$. The antiproliferative activity was determined using a 3-(4,5-dimethylthiazol-2-yl)-2,5-diphenyltetra-zolium bromide assay $\left({ }^{* *} \mathrm{P}<0.01\right.$ compared with the control).

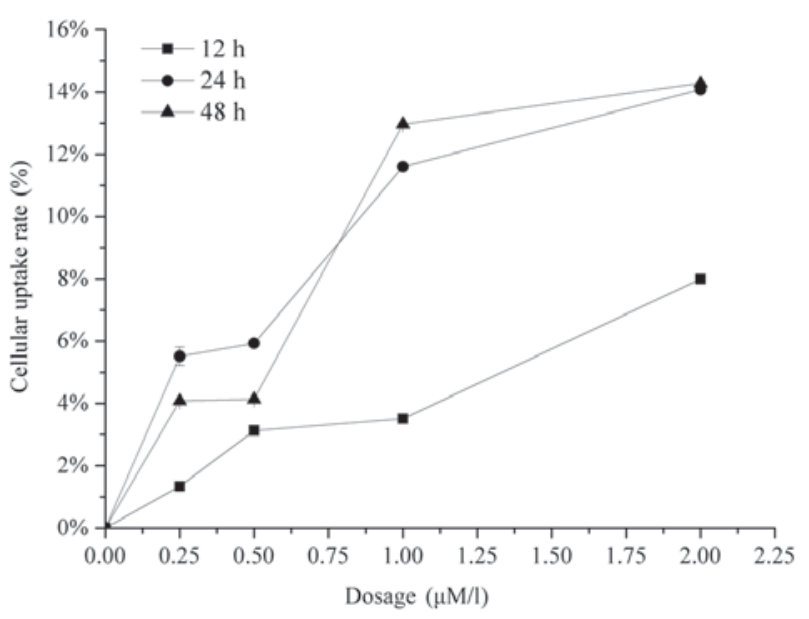

Figure 2. Cellular uptake rate of Raddeanin A in HCT-116 cells following incubation for 12,24 and $48 \mathrm{~h}$ with $0.25,0.5,1$ and $2 \mu \mathrm{M}$ of Raddeanin A. 

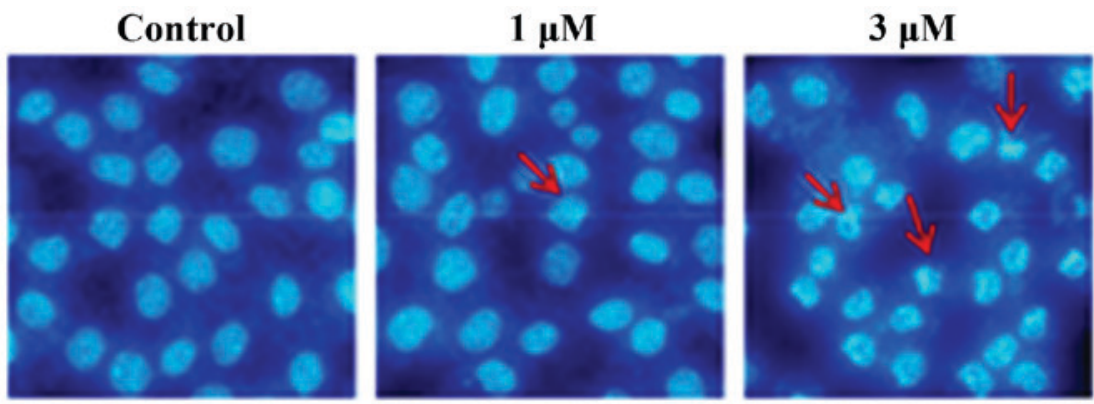

Figure 3. Cell nuclear morphometry of HCT-116 cells following staining with DAPI dye. The images shows control cells and cells treated with 1 and $3 \mu \mathrm{M}$ of Raddeanin A for 24 h, respectively. The red arrows identify broken nuclei in the Raddeanin A-treated cells. Magnification, x200.
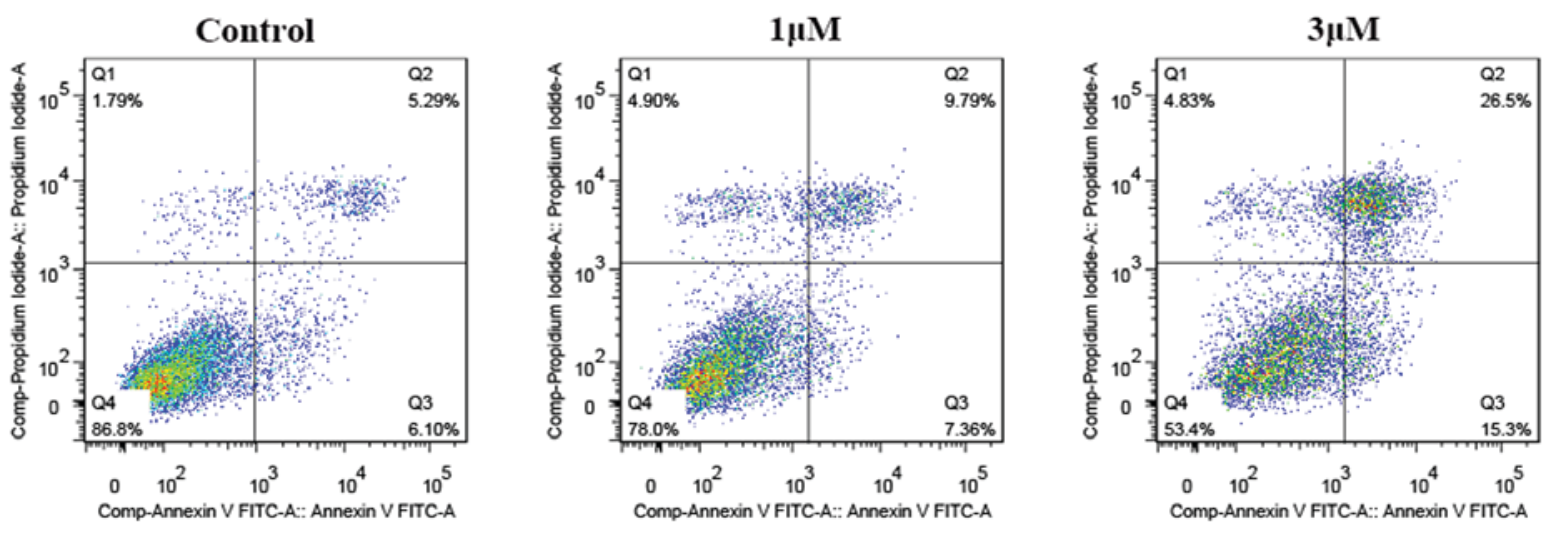

Figure 4. Flow cytometric analysis of HCT-116 cell apoptosis induced by Raddeanin A using FITC-annexin/PI staining. The lower left quadrant shows living cells $\left(\mathrm{FITC}^{-} / \mathrm{PI}\right)$. The lower right quadrant shows apoptotic cells $\left(\mathrm{FITC}^{+} / \mathrm{PI}^{-}\right)$. The upper left quadrant shows necrotic cells $\left(\mathrm{FITC}^{-} / \mathrm{PI}^{+}\right)$. FITC, fluorescein isothiocyanate PI, propidium iodide.

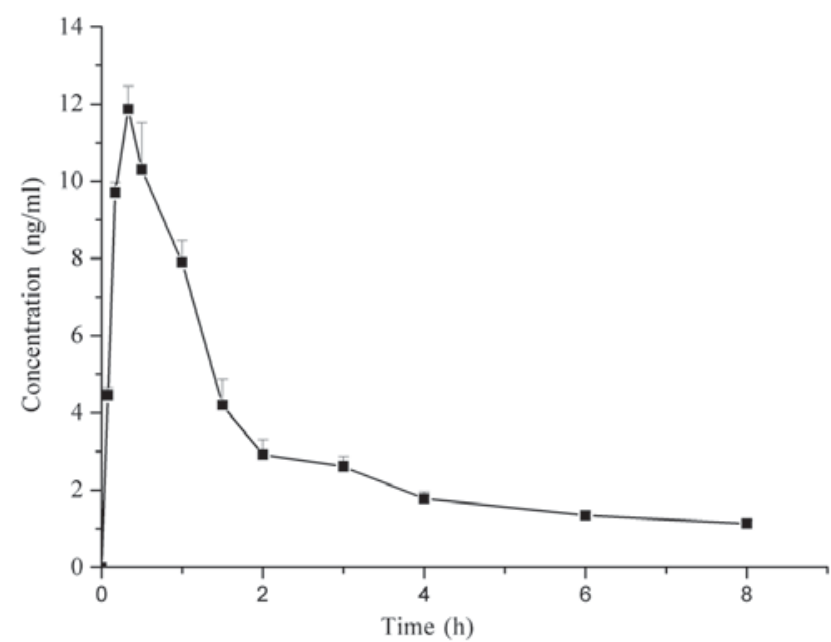

Figure 5. Mean plasma concentration-time curve of Raddeanin A following oral administration.

a non-compartmental model are presented in Table I. Raddeanin A was absorbed rapidly in vivo, with a time to maximum concentration of $0.33 \mathrm{~h}$. The concentrations detected in the plasma were low, with a maximum concentration of $12.326 \mu \mathrm{g} / \mathrm{l}$. This was consistent with a previous study (7), in which low bioavailability of Raddeanin A was demonstrated. In addition, Raddeanin A showed fast elimination with a half-life of $3.542 \pm 0.158 \mathrm{~h}$ and was undetectable in the plasma at $6 \mathrm{~h}$.

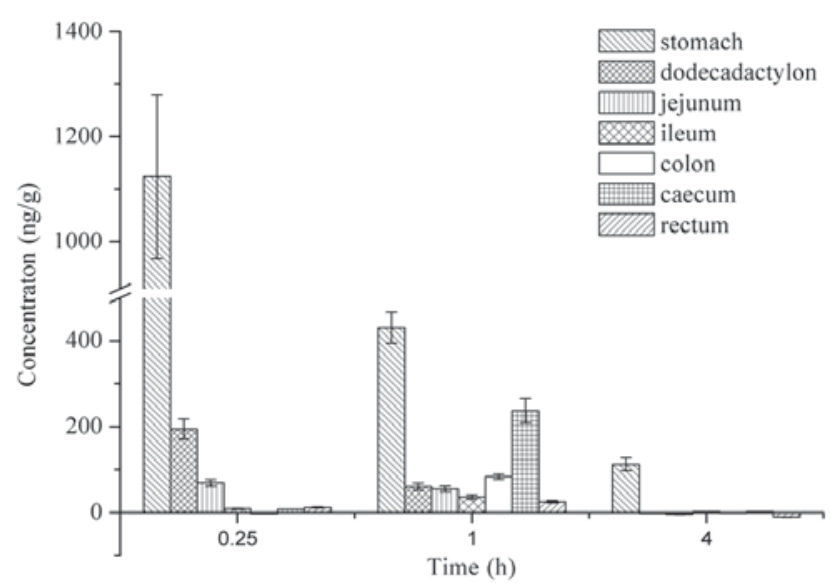

Figure 6. Concentrations of Raddeanin A in the intestinal tissues following oral administration.

Tissue distribution. The in vivo distribution of Raddeanin A was examined by the quantitative detection of the levels of Raddeanin A in different tissues (Fig. 6). Following oral administration, Raddeanin A was detected in various gastrointestinal tract tissues, namely the stomach, dodecadactylon, jejunum, ileum, colon, caecum and rectum. The highest level of Raddeanin A was observed in the stomach, followed by the colon and the caecum. At $4 \mathrm{~h}$, Raddeanin A was almost undetectable in any of the intestinal tract. In terms of the 
distribution of Raddeanin A in the blood perfused organs, including the heart, liver, spleen, lung and kidney, the drug levels were not sufficient to be detected using the method used. This was predominantly due to the low absorption of Raddeanin A in the plasma following oral administration, as described above.

\section{Discussion}

In ancient time, traditional Chinese medicines were widely used. Investigations have demonstrated the association between the structure of triterpene saponin and its anticancer activities (8) and Raddeanin A, as a triterpene saponin, was one of the primary active components. However, there are no reports on its apoptosis-inducing effect on HCT-116 human colon cancer cells. In addition the cellular uptake patterns of Raddeanin A have not been reported. In the present study, a validated LC-MS/MS method was used to examine cellular uptake, and pharmacokinetic investigations were performed.

In the cell experiments, Raddeanin A was observed to inhibit the proliferation of HCT-116 cells in a dose dependent manner. The $\mathrm{IC}_{50}$ was $1.413 \mu \mathrm{M}$, which was lower, compared with that reported in a previous study on human gastric cancer cells (4). DAPI staining and flow cytometric analysis of apoptosis demonstrated the apoptosis-inducing effect of Raddeanin A on the HCT-116 cells. The cellular uptake of Raddeanin A in the HCT-116 cells occurred in a dose-dependent manner.

The pharmacokinetic and tissue distribution characteristics of Raddeanin A were measured in mice. In the pharmacokinetic investigations, a previously developed validated analytical method was utilized to successfully detect the concentrations in mice plasma. The results showed the rapid distribution and elimination of Raddeanin $\mathrm{A}$, which was in agreement with a previous study, which indicated that low bioavailability leads to low concentrations in plasma (7). By contrast, examination of the tissue distribution in the present study demonstrated that Raddeanin A was predominantly distributed in the gastrointestinal tract. Considering its effective antiproliferative activity on human colon cancer cells, Raddeanin A is a promising candidate for the treatment of superficial gastrointestinal cancer.

The present study demonstrated that the Raddeanin A from Ranunculaceae Anemone raddeana induced the apoptosis of HCT-116 cells, which, to the best of our knowledge, has not been reported previously. The uptake of Raddeanin A in HCT-116 was investigated, and the result showed dose-dependency. Additionally, the determination of
Raddeanin A in mouse intestinal tissues demonstrated that Raddeanin A was predominantly distributed in the stomach, followed by the cecum and colon. The cell experiments and pharmacokinetic investigations performed support the use of Raddeanin A as a potential oral drug for the treatment of superficial colon cancer in the future. As saponin injection has several harmful adverse effects, including hemolysis (9), the exploitation of a non-injectable formulation for Raddeanin A is necessary.

\section{Acknowledgements}

This study was supported by the State Key Laboratory of Materials-Oriented Chemical Engineering, Nanjing Tech University (grant no. KL14-08) and the National Science and Technology Major Projects for 'Major New Drugs Innovation and Development' (grant no. 2013ZX09103001-004).

\section{References}

1. Cao P, Wu FE and Ding LS: Advances in the studies on the chemical constituents and biologic activities for anemone species. Nat Prod Res Dev 16: 581-584, 520, 2004.

2. Zhang JM, Cao L and Wu ZM: Studies on anticancer activities of triterpenoid in Anemone raddeana Regel. Chinese J New Drugs 12: 191-193, 2003 (In Chinese).

3. Ma M, Li DL, Zhao DY, et al: Study the effect of raddeanin A on the proliferation of human hepatic cancer in nude mice. Drug Eval Res 01: 40-43, 2015. (In Chinese).

4. Xue G, Zou X, Zhou JY, Sun W, Wu J, Xu JL and Wang RP: Raddeanin A induces human gastric cancer cells apoptosis and inhibits their invasion in vitro. Biochem Biophys Res Commun 439: 196-202, 2013.

5. Wang MK, Ding LS and Wu FE: Antitumor effects of raddeanin A on S180, H22 and U14 cell xenografts in mice. Ai Zheng 27: 910-913, 2008 (In Chinese).

6. Sun C, Li Q, Pan L, Liu B, Gu P, Zhang J, Ding L and Wu C: Development of a highly sensitive LC-MS/MS method for simultaneous determination of rupatadine and its two active metabolites in human plasma: Application to a clinical pharmacokinetic study. J Pharm Biomed Anal 111: 163-168, 2015.

7. Liu Y, Ma B, Zhang Q, Ying H, Li J, Xu Q, Wu D and Wang Y: Development and validation of a sensitive liquid chromatography/ tandem mass spectrometry method for the determination of raddeanin $\mathrm{A}$ in rat plasma and its application to a pharmacokinetic study. J Chromatogr B Analyt Technol Biomed Life Sci 912: 16-23, 2013.

8. Cao J, Li W, Tang Y, Zhang X, Li W and Zhao Y: Three new triterpene saponins from Actinostemma lobatum MAXIM and their cytotoxicity in vitro. Phytochem Lett 11: 301-305, 2015.

9. Zhou HL, Shun YX, Li Y, Wang B and Liu DY: Progress in Studies on Chemical Constituents and Pharmacological Effect of Anemone raddeana Regel. Lisizhen Medicine and Materia Medica Research 05: 1239-1241, 2007. (In Chinese). 